$5-10-2011$

\title{
Strengthening Africa's Contributions to Child Development Research: Introduction
}

Kofi Marfo

Aga Khan University, kofi.marfo@aku.edu

Alan Pence

University of Victoria

Robert A. LeVine

Harvard University

Sarah LeVine

Harvard University

Follow this and additional works at: https://ecommons.aku.edu/eastafrica_ihd

Part of the Early Childhood Education Commons

\section{Recommended Citation}

Marfo, K., Pence, A., LeVine, R. A., LeVine, S. (2011). Strengthening Africa's Contributions to Child Development Research: Introduction. Child Development Perspectives, 5(2), 104-111.

Available at: https://ecommons.aku.edu/eastafrica_ihd/6 


\title{
Strengthening Africa's Contributions to Child Development Research: Introduction
}

\author{
Kofi Marfo, ${ }^{1}$ Alan Pence, ${ }^{2}$ Robert A. LeVine, ${ }^{3}$ and Sarah LeVine ${ }^{3}$ \\ ${ }^{1}$ University of South Florida, ${ }^{2}$ University of Victoria, and ${ }^{3}$ Harvard University
}

ABSTRACT_The articles in this Special Section are based on contributions to an SRCD-sponsored invitational conference held in Victoria, Canada, in February 2009. This introductory article establishes the rationale for focusing on Africa as part of an effort to advance a more inclusive science of child development, provides a brief overview of the thrust of the other articles in the section, describes 2 research capacity-building initiatives that emerged from the conference, and concludes with reflective perspectives on conceptual and methodological considerations for a future African child development field.

KEYWORDS—child development in Africa; research capacity building; culture and child development research; disciplinary and methodological integration; theoretical integration

The articles in this Special Section resulted from the invitational conference Strengthening Africa's Contributions to Child Devel-

The conference for which the articles in this Special Section were prepared was cosponsored by the Society for Research in Child Development and the Investigating Quality (IQ) Project at the University of Victoria, Canada. The study group gratefully acknowledges team members Dr. Cigdem Kağitçibaşi, Dr. Robert G. Myers, and Dr. A. Bame Nsamenang, whose contributions are briefly abstracted in this article, and Dr. Veronica Pacini-Ketchabaw, IQ Project Co-Investigator, for her participation and support throughout the conference. The team is also thankful to Marie-Germaine Chartrand, Lynette Jackson, and Debbie Blakely of the University of Victoria for organizational and logistical support. The first author is thankful to the Center for Advanced Studies in the Behavioral Sciences at Stanford University, where much of his contribution to the final version of this article was written.

Correspondence concerning this article should be addressed to Kofi Marfo, Department of Psychological and Social Foundations, University of South Florida-EDU105, 4202 E. Fowler Avenue, Tampa, FL 33620; e-mail: marfo@usf.edu.

(c) 2011 The Authors

Child Development Perspectives @ 2011 The Society for Research in Child Development opment Research, held in Victoria, Canada, in February 2009. The conference was conceived in response to Society for Research in Child Development's (SRCD) call in late 2007 for proposals from its membership to pursue small-group scholarly activities that could advance the Society's values and strategic priorities regarding multidisciplinarity, cultural and contextual diversity, and international perspectives in child development research. The conference conveners (Marfo and Pence) welcomed the call as an opportunity not only to raise awareness about the underrepresentation of non-Western knowledge contributions to child development inquiry but also to create a forum for an international, interdisciplinary group of scholars to examine the African context specifically. The group encompassed a diverse blend of expertise and backgrounds—anthropology, early childhood care and development, economics, education, and psychology - and its work was cast in the larger context of advancing a science of child development that opens up to populations and possibilities outside the Euro-American world (Pence \& Marfo, 2008).

\section{THE CASE FOR FOCUSING ON AFRICA}

As is evident from the analysis by Super, Harkness, Barry, and Zeitlin (this issue), it can be argued that Africa already occupies a position of importance in the history of cross-cultural research by virtue of its attractiveness to early investigators searching for universal patterns in human development or seeking to test the generalizability of Western theories. Influential footprints from investigations carried out on the continent by expatriate scholars, especially in the second and third quarters of the 20th century, are evident today not only in culture-informed domain-specific theorizing —in areas such as attachment (e.g., Ainsworth, 1967, 1977), socialization (e.g., LeVine, 1974, 1988; LeVine, Dixon, LeVine, Richman, et al., 1994; LeVine \& LeVine, 1988), motor development (e.g., Leiderman, Babu, Kagia, Kraemer, \& Liedeman, 1973; Super, 1976), and cognition (e.g., Cole, Gay, 
Glick, \& Sharp, 1971)—but also in broader conceptual frameworks for understanding contextual influences on human development generally (e.g., Harkness \& Super, 1992a, 1992b; Super \& Harkness, 1986). These contributions, along with newer generations of itinerant research, have been published extensively in North American and international journals and in specialized monographs and collective volumes from major publishing houses. They are easily accessible to scholars from all over the world, barring resource limitations.

A different picture emerges when the focus is shifted from the long tradition of expatriate research to contributions by resident African scholars approaching the study of African children through lenses and questions grounded in the continent's realworld dynamics and challenges. In many regards, the power dynamics between rich and poor societies_-as reflected in differential access to research funding opportunities, publication avenues, and major conferences, and in other means of professional gate-keeping-virtually ensure the marginalization of intellectual agendas contemplated outside the Western academy (Pence \& Marfo, 2008). It is always possible to point to a few pieces of evidence suggesting that things are improving, but, indisputably, scholarly perspectives on issues with conceptual and practical relevance to Africa do not find ready acceptance in leading Western journals. This is in part because the point of reference for determination of relevance in these journals is often the Euro-American worldview (Arnett, 2008).

In Africa in particular, research funding is virtually nonexistent, and outlets for dissemination of the little research that is produced - funded or otherwise-are sparse. With limited, often delayed access to current literature from other parts of the world, many scholars in Africa are rendered noncompetitive in their efforts to publish their work in major international journals. The net result of these conditions is that much of the research conducted by African scholars on the continent is confined to a gray literature, the expanse and content of which should itself be a subject for research. The gray literature is defined to include unpublished theses (master's and doctoral), working papers, technical research reports, conference proceedings, as well as scholarship appearing in periodicals and monographs with limited circulation beyond the issuing institution. In an article assessing cognitive development research on the continent, Serpell (1984) noted that as a result of challenges such as those highlighted here, "a systematic survey of trends in the research being undertaken on the continent is easier to conduct from outside Africa than from inside" (p. 113).

This picture has not changed much even with advances in information and communication technologies, although there is a bright spot worth highlighting here. Under the auspices of the Association of African Universities (AAU), the Database on African Theses and Dissertations (DATAD; http:/www.aau.org/ datad/) was launched recently with funding from the Ford and Rockefeller foundations. Along with other virtual-library initiatives around the continent, DATAD should begin to fill some of the gap, but full-text access to documents through the emerging platforms is still years away. DATAD is just one example of how Africa's higher education institutions (HEIs) are responding to the critical need for capacity-building and infrastructural development activities to advance research across all disciplines. This need was underscored in initiatives launched by the AAU to position HEIs to assume a major role as positive change agents across the continent and to enable African scholars to strengthen their role in research and policy analysis. The AAU's 1999 Strategic Plan objectives, embedded later in the core program of activities for 2005-2009, included the following foci: (a) strengthening the capacity of African universities for knowledge generation and dissemination and (b) enhancing the voice and recognition of African HEIs through increased presence and influence on continental and overseas bodies (http://www.aau. org/coreprog/0509/CP2005-09.pdf).

Our study group's work at the conference aimed for two complementary outcomes regarding research capacity building in Africa. First, in synergy with other initiatives on the continent-such as the regional research workshops organized by the International Society for the Study of Behavioral Development (ISSBD) and the International Association for Cross-Cultural Psychology (IACCP)—we expected the capacity-building initiatives emerging from our work to serve as one model of how the AAU's own strategic goals might be achieved. Second, we hoped that our work would give SRCD enhanced representation in efforts by international research organizations to support inquiry and research education in Africa.

It may be tempting to view Africa's disadvantage in knowledge production and dissemination as an African problem, but while many of the issues raised here have been framed in terms of Africa because of our project's specialized focus, they are applicable to other parts of the non-Western world. Thus, left unaddressed, the constraints to knowledge production and dissemination identified here will only serve to perpetuate the contextually slanted nature of existing knowledge, undercutting the credibility of any claims that might be made about a global knowledge base.

\section{PROJECT GOALS AND OUTCOMES}

The conference was organized to: (a) examine the status and needs of the child development field in Africa, (b) share perspectives on what it means to institutionalize child development research on the continent, (c) present insights from research programs and practice initiatives on the continent, and (d) identify networking and capacity-building needs for future action. The first three goals were addressed through working papers-prepared and distributed ahead of the conference-providing the foundation for the scholarly deliberations, while the final goal served to ensure that a substantial part of the group's time was devoted to discussion and strategic planning toward research capacity building on the continent. In the remainder of this 
article, we provide a brief orienting framework for the contributions in this Special Section, introduce the central research capacity-building proposal emerging from the conference, and present some reflections on the prospects and challenges of advancing culturally grounded inquiry in Africa.

The articles in this Special Section are only a subset of the working papers discussed at the Victoria conference (there were other contributions with relevant lessons for Africa that were not focused directly on the continent), but they do reflect the diversity of perspectives resulting from the selection of scholars for the study group. At an initial classificatory level, there are two broad kinds of contributions, those addressing the general challenge of institutionalizing and supporting child development research on the continent and those synthesizing empirical and theoretical insights from past and current research. Beyond that, several themes are discernible from the articles as a collection: a cultural-historical critique of the Westernization of childhood and child development research in Africa (Pence); a synthesis of contributions that Africa has made to a global field through the work of expatriate scholars (Super, Harkness, Barry, \& Zeitlin); an integration of insights and lessons from a sustained program of research on the continent by a resident African scholar (Serpell); insights from an applied research program that could serve as a model for building systematic inquiry into communitybased services (Mwaura \& Marfo); and a visioning about disciplinary development on the continent (Marfo). The scholarly contributions constituted only one half of the study group's work. The other half consisted of strategic planning of how best to support research capacity building. In the remainder of this section, we provide a quick overview of that part of the group's work.

\section{Strategies to Support Research Capacity Building}

The health and developmental challenges facing the world's poorest children continue to receive the attention of the research and development assistance communities (Garcia, Pence, \& Evans, 2008; Walker, Wachs, Gardner, Lozoff, et al., 2007). Africa has an extremely high and disproportionate representation of children at risk for serious developmental and health problems. Even as United Nations agencies, donor nations, and private foundations make fiscal investments in programs to address African children's problems, very little of the research that exists to provide guidance on how to address these problems has been conducted on the continent (see recent Lancet articles by the International Child Development Steering Group; e.g., Engle, Black, Behrman, de Mello, et al., 2007; Grantham-McGregor, Cheung, Cueto, Glewwe, et al., 2007).

Generation of the locally relevant knowledge base that is needed to guide policies and interventions cannot be sustained unless there is sufficient local expertise capable of conducting conceptually and methodologically sound research. The study group's deliberations on research capacity building culminated in the articulation of a two-pronged strategy combining the institutionalization of model field research programs with support for the preparation and mentoring of new generations of researchers on the continent.

\section{A Regional Multisite Field Research Model}

Under the first strategy, the study group developed the broad outlines of what could ultimately become a proposal to seek grant support from a consortium of funding agencies to establish a sustainable multisite longitudinal research program. The research would be designed and directed by scholars on the continent and carried out within a network of three regional sites, one each for West, East, and Southern Africa.

The design of the program would have the benefit of insights gained from the structuring and management of large-scale research programs that have demonstrated impressive success and sustainability in regions of the world with economic and geopolitical circumstances similar to Africa's. It would also be informed by longitudinal projects of a much smaller scale emphasizing child health and development outcomes. Examples of the former include the still-running biomedical surveillance program begun in Matlab, Bangladesh, in the 1960s (see Aziz \& Mosley, 1997) and the more recent Cebu Longitudinal Health and Nutrition Study involving a cohort of Filipino women and their children born between May 1983 and April 1984 (The Cebu Study Team, 1991). Examples of the latter include the intervention studies at the Institute of Nutrition in Central America and Panama (INCAP) between 1969 and 1977 (Townsend et al., 1982; Scrimshaw \& Guzman, 1997) and, closer to home, South Africa's Birth to Ten/Twenty study (Barbarin \& Richter, 2001; Richter, Norris, Pettifor, Yach, \& Cameron, 2007). Apart from being on the continent, the South African project is uniquely relevant because the project's designers struggled through, and explicitly addressed, challenges in reconciling recognition of culture-specific conceptions of developmental phenomena and the compromised use of Western instruments (Barbarin \& Richter, 2001).

Among other design considerations, the proposed multisite project will follow large cohorts of children, employing child-, context-, and systems-level variables to generate a variety of data forms. Particular attention will be paid to child and maternal health indicators, including immunizations and other forms of health monitoring and promotion; developmental functioning across culture-relevant domains; psychological well-being, including supports and resources for coping with adversity; changing patterns in children's roles and responsibilities; socialization processes within the family and community; schooling processes and outcomes; and individual as well as community responses to social change at the macro level. The project will be designed as an open system with enough flexibility to support the spawning of satellite studies on any number of specific questions employing a wide range of methodologies. Historical and ethnographic investigations of children's adaptation to different conditions will be as valuable as experimental and quasi-experimental studies exploring all types of interaction 
effects-Person $\times$ Context $\times$ Treatment (in intervention studies of special populations) or even Gene $\times$ Environment $\times$ Treatment interactions (in studies of specific behavioral traits).

\section{A Mentoring Model of Research Education}

Under the second strategy, we envisioned a two-stage initiative for supporting research capacity building. Complementing existing regional initiatives on the continent, such as those sponsored by the IACCP and the ISSBD, the first was to support in the near term a mentorship program for scholars in the earliest stages of their academic careers. One approach under consideration employs a triadic model, with each mentorship unit consisting of (a) an early career-stage scholar in an African university, (b) a senior African scholar in the same or another university who will serve as the direct mentor, and (c) an Africa-knowledgeable senior scholar from an overseas institution who would provide consultation and assist with resource targeting and collaborative research. When in place, the regional, multisite field research model described in the previous section will serve as one context for the second stage of the mentorship initiative. Research internships and postdoctoral fellowship appointments on on-going research projects at the various sites will constitute an important medium for research education and mentorship.

In the months following the Victoria conference, the team leaders have taken steps toward establishing the first mentoring initiative. Utilizing conferences and research workshops occurring on the continent, they have begun to establish a networking process that is helping to identify scholars who might benefit from the mentoring program. In July 2010, the first workshop under the mentoring initiative was convened in Lusaka by co-team leader Alan Pence, with funding from UNICEF's East and Southern Africa Regional Office. Limited at that stage to the field of early childhood development, the workshop was framed around the two Africa-based components of the triadic model.

\section{AFRICAN RESEARCH AND THE ADVANCEMENT OF A GLOBAL SCIENCE: SOME PROPOSALS}

Running through the conference goals and the resulting scholarly contributions are two intertwined endpoints: (a) African research that is driven by the quest for solutions to problems and issues facing African children, families, communities, and nations and (b) African research that advances a global science of child development. We devote this final section to a reflective discussion of issues that might guide such research, beginning with the proposition that the institutionalization of child development inquiry in Africa provides opportunities for the advancement of a truly global field. However, neither the indiscriminate rejection of everything Euro-American nor the wholesale importation of Western theories, methodologies, and practices would position Africa to contribute to such advancement. If the capacity-building strategies outlined above are to promote inquiry that is as relevant to Africa as it is to a global field, the issues framed here deserve consideration.

\section{Inquiry as a Cultural Project}

The values that define important problems, and the paradigmatic and methodological frameworks that guide the resulting inquiry, are grounded in cultural conceptions and traditions (Marfo, this issue), much the same way as conceptions of childhood and the childrearing practices they engender are rooted in the lived experiences and worldviews of cultural communities (Dawes \& Donald, 2000; Zimba, 2002). In this sense, problems and issues relating to the lives of children in family, community, and national contexts will be at the core of an African child development research enterprise. Each of the articles in this Special Section has highlighted one or more of these issues. Socially distributed childrearing is one subject on which African research has a great deal to contribute to a global knowledge base because African socialization models contrast so sharply with the predominant dyadic, parent-child (mostly mother-child) model in Euro-American research. We highlight here additional problem areas in need of attention.

The generation of normative milestones for various domains of development is one such important problem area. Developmental norms and population-based indicators of health and well-being, along with careful documentations of life circumstances and ecological assets within local communities, are crucially important not only for the advancement of basic research but also for the design and evaluation of policies and interventions. On this as on other issues, the imperative to complement and extend, rather than supplant, what is known from Western developmental science cannot be overemphasized. Research dedicated to the design and local validation of developmental assessment tools, even if based mostly on domains typically found on Western instruments, is very important. Recent examples of efforts in this direction can be found in East Africa where collaborations involving African, European, and U.S. research institutions are producing locally validated tools for use in Kenyan village settings (e.g., Abubakar, Holding, Van Baar, Newton, \& Van de Vijver, 2008; Abubakar, Holding, Van de Vijver, Bomu, \& Van Baar, 2010; Abubakar et al., 2007).

Additional areas for potentially groundbreaking work include conceptualization, measurement, and generation of local norms for attributes and behaviors valued by families and communities as important developmental goals in childrearing. These developmental assets and milestones would not register on the radar of many Euro-American developmental assessment tools, and yet they matter very much in local contexts. Consider for a moment some of the attributes that Beatrice Whiting's work has identified as character traits that Kikuyu mothers in Kenya prefer to see in their children: confidence, inquisitiveness, cleverness, bravery, good-heartedness, respectfulness, obedience, and generosity (Weisner, 2000; Whiting, 1996). Consider yet 
other attributes: hospitality, empathy, sharing, social responsibility, sense of belonging, patience, attentiveness, and many others. Focused interviews, observations, and thorough analysis of folklore, proverbs, riddles, group games, and other activities would reveal that these are all socially valued attributes within African communities. What are ways to measure these attributes? What life outcomes (school related or otherwise) are predictable from measures derived from any combination of these traits? These are significant questions that should spur conceptual and empirical contributions with local and global implications.

There are sociopolitical imperatives as well for the kinds of research anticipated in the preceding paragraph. In an era when African and other non-Western cultural values and practices are under attack as barriers to socioeconomic and political progress (Etounga-Manguelle, 2004; Harrison, 2004; Huntington, 2004) — when culture change is being promoted in some circles as a potentially more viable strategy for international development aid than traditional economics-driven strategies (see Harrison \& Huntington, 2004), and when the winds of globalization appear to be carried by an implicit evolutionist view of human advancement as progression toward Euro-American social, economic, and political values (see Pence, this issue) - there is no better time than now for African researchers to take seriously, as a cultural project, empirical exploration of the complex relationships between socialization values and practices on the one hand and child and national developmental outcomes on the other.

Regardless of the value judgments that globalization may trigger, it presents another imperative for increased applied developmental research in non-Western societies. Our children's lives are now lived at the intersection of local realities and inevitable forces of global change. Many children are being thrust into multiple worlds, in none of which they feel at home. How do formal and informal agents of socialization prepare children with the competencies necessary to function optimally across contexts? Child development research has an important role to play by forging a better understanding of the competencies, attitudes, and emotional resources children need and use to navigate within and across different environments.

\section{Disciplinary and Methodological Integration}

It is impossible to develop comprehensive understandings about children's development without building into the anticipated models of inquiry relevant perspectives and methods from the broad range of disciplines concerned with children's development-anthropology, cognitive science, neuroscience, developmental and behavioral pediatrics, education, nutritional science, psychology, public/population health, sociology, and so on. In his contribution to the Victoria conference, Myers (2009) addressed the challenges of disciplinary insularity and made the following compelling case for multidisciplinarity in child development inquiry:
. . . child development, like education, is a "field of study" to which many disciplines can and should be applied. If there is a "science" of child development it sits at the meeting point of these disciplines. (p. 13)

The call for multiple methods is neither a case for sheer equity in the representation of quantitative and qualitative methods nor a simplistic admonition for the combined use of methodological genres. It is premised on the principles that (a) across disciplines, different epistemological and theoretical perspectives trigger different research questions, which in turn call for correspondingly relevant methods, and (b) the knowledge resulting from these multiple forms of inquiry contribute legitimately to broader understandings about child development. Thus, the anticipated programs of inquiry and mentoring should embrace various forms of systematic, rigorous investigation employing different designs (quantitative experimental/nonexperimental; qualitative/interpretive) and different forms of data-gathering strategies: naturalistic observations, surveys, quantitative measurement, discourse analysis, self-reports, diaries, and so forth. While the state of the "science" of child development may not yet reflect a deep commitment to this level of methodological pluralism, there are signs, especially within cultural and crosscultural psychology, that this is a valued ideal (see Dasen \& Mishra, 2000; Greenfield, 1997). If an African child development field is to transcend the traditional boundaries of psychological inquiry to include anthropological, economic, historical, political, and sociological perspectives, a deepening of this value is critical, and at both the disciplinary and methodological levels, an ethic of complementarity (Eckensbeger, 2002) is axiomatic.

\section{Theoretical Integration}

Especially because much of our argument for systematic institutionalization of child development research in non-Western societies is premised on the idea that Western behavioral science gives insufficient attention to cultural relativity, it is important to underscore here that African research cannot afford to commit an error in the opposite direction and frame development as if cultural influences are all that matter. Neither, as Nsamenang (2009) notes in his conference contribution, should advocacy for cultural sensitivity pass for "cultural essentialism, scientific isolationism, [or] dismissal of the extant body of knowledge . . . gained through more than a century of child development research" (p. 5). An African field with the prospect of contributing to a global knowledge base is better served by an orientation that fosters theoretical integration in all its varied manifestations. One basic example of such integration is the framing of development as the product of constitutional (genetic as well as nongenetic), social, economic, and cultural factors interacting in linear and nonlinear ways throughout the lifespan, such that none of these determinants alone can explain development satisfactorily (Horowitz, 2000). 
A second example of theoretical integration that is particularly germane to African research is captured by Super et al. (2011). Through the constructs of ecocultural niche, developmental microniche, and developmental niche, Weisner (1984), Worthman (1994), and Super and Harkness (1986, 2002) have, respectively, synthesized bodies of research on various conceptions of the cultural environment (as a social setting for daily life; as customary practices, and as caregivers' shared beliefs/ethnotheories) into more comprehensive explanatory frameworks. As Super and Harkness (1997) note, these metatheoretical frameworks contribute transcendent insights into how the various cultural environments are interconnected with each other and with the wider developmental ecology, including endogenous factors.

A third example of integration is seen in Kağitçibaşi's (2009) response to false assumptions in debates on culture and human development-that is, false uniqueness (depicting a phenomenon as unique to a given culture when it may exist in other cultures) and false universality (assuming commonality across cultures when there is none). To illustrate, as Euro-American psychology has depicted autonomy and relatedness as contrasting attributesoften privileging the former over the latter-cross-cultural psychology has associated autonomy with individualistic societies and relatedness with collectivist ones. In her contribution to the Victoria conference, Kağitçibaşi addressed the misnomer in psychology's portrayal of these two attributes as incompatible and/or exclusively culture specific. Her work (Kağitçibaşi, 2007) illustrates how research in a non-Western society (Turkey) can contribute the level of integration evident in her theory of the autonomous-related self - the idea that autonomy and relatedness can and do co-exist in individualistic and collectivist societies-which she sees as a model of healthy self across cultures. The African context is ripe for inquiry with the potential to extend such integrative theorizing.

\section{CONCLUSION}

The SRCD articulated its strategic goals on multidisciplinarity, cultural/contextual diversity, and international perspectives in research at a time of gradual awakening to the reality that what is known about children's development is based on investigation of a very small percentage of the world's children (Arnett, 2008; Pence, this issue; Stevens \& Gielen, 2007). The study group's work on Africa was undertaken in the hope of helping to advance an authentic global science of child development. One of the challenges facing that ideal science today is how to support research capacity around the developing world to promote and support rigorous research that grows out of the local, reflects the interests and hopes inherent in that world, and contributes unique insights to a global discipline. It is an immense undertaking, but one that must be pursued. We hope that the focus on Africa adds a little bit of momentum to existing initiatives aimed at strengthening the continent's contributions to scientific knowledge.

\section{REFERENCES}

Abubakar, A., Holding, P., Van Baar, A., Newton, C. R. J. C., \& Van de Vijver, F. J. R. (2008). Monitoring psychomotor development in a resource-limited setting: An evaluation of the Kilifi Developmental Inventory. Annals of Tropical Pediatrics, 28, 217-226.

Abubakar, A., Holding, P., Van de Vijver, F. J. F., Bomu, G., \& Van Baar, A. (2010). Developmental monitoring using caregiver reports in a resource-limited setting: The case of Kilifi, Kenya. Acta Pediatrica, 99, 291-297.

Abubakar, A., Van de Vijver, F. J. R., Mithwani, S., Obiero, E., Lewa, E., Kenga, S., et al. (2007). Assessing developmental outcomes in children from Kilifi, Kenya, following prophylaxis for seizures in cerebral malaria. Journal of Health Psychology, 12, 417-430.

Ainsworth, M. D. S. (1967). Infancy in Uganda. Baltimore: Johns Hopkins University Press.

Ainsworth, M. D. S. (1977). Infant development and mother-infant interaction among Ganda and American families. In P. H. Leiderman, S. R. Tulkin, \& A. Rosenfeld (Eds.), Culture and infancy (pp. 119-149). New York: Academic Press.

Arnett, J. J. (2008). The neglected 95\%: Why American psychology needs to become less American. American Psychologist, 63, 602-614.

Aziz, K. M. A., \& Mosley, W. H. (1997). The history, methodology, and main findings of the Matlab project in Bangladesh. In M. S. Das, P. Aaby, M. Garenne, \& G. Pison (Eds.), Prospective community studies in developing countries (pp. 28-53). Oxford, UK: Oxford University Press.

Barbarin, O. A., \& Richter, L. M. (2001). Mandela's children: Growing up in post-Apartheid South Africa. New York: Routledge.

Cebu Study Team. (1991). Underlying and proximate determinants of child health: The Cebu Longitudinal Health and Nutrition Study. American Journal of Epidemiology, 133, 185-201.

Cole, M., Gay, J., Glick, J. S., \& Sharp, D. W. (1971). The cultural context of learning and thinking: An exploration in experimental anthropology. New York: Basic Books.

Dasen, P. R., \& Mishra, R. C. (2000). Cross-cultural views on human development in the third millennium. International Journal of behavioral Development, 24, 428-434.

Dawes, A., \& Donald, D. (2000). Improving children's chances: Developmental theory and effective interventions in community contexts. In D. Donald, A. Dawes, \& J. Louw (Eds.), Addressing childhood adversity (pp. 1-25). Cape Town, South Africa: David Philip.

Eckensbeger, L. H. (2002). Paradigms revisited: From incommensurability to respected complementarity. In H. Keller, Y. H. Poortinga, \& A. Scholmerich (Eds.), Between culture and biology: Perspectives on ontogenetic development (pp. 341-383). Cambridge, UK: Cambridge University Press.

Engle, P. L., Black, M. M., Behrman, J. R., de Mello, M. C., et al. (2007). Strategies to avoid the loss of developmental potential in more than 200 million children in the developing world. Lancet, 369, 229-242.

Etounga-Manguelle, D. (2004). Does Africa need a cultural adjustment program? In L. E. Harrison \& S. P. Huntington (Eds.), Culture matters: How values shape human progress (pp. 65-77). New York: Basic Books.

Garcia, M., Pence, A., \& Evans, J. (Eds.) (2008). Africa's future, Africa's challenge: Early childhood care and development in Sub-Saharan Africa. Washington, DC: The World Bank. 
Grantham-McGregor, S., Cheung, Y. B., Cueto, S., Glewwe, P., et al. (2007). Developmental potential in the first 5 years for children in developing countries. Lancet, 369, 60-70.

Greenfield, P. M. (1997). Culture as process: Empirical methods for cultural psychology. In J. W. Berry, Y. H. Poortinga, \& J. Pandey (Eds.), Handbook of cross-cultural psychology: Vol. 1. Theory and method (2nd ed., pp. 301-346). Boston: Allyn \& Bacon.

Harkness, S., \& Super, C. M. (1992a). Shared child care in East Africa: Sociocultural originas and developmental consequences. In M. E. Lamb, K. J. Sternberg, C. P. Hwang, \& A. G. Broberg (Eds.), Child care in context: Cross-cultural perspectives (pp. 441-459). Hillsdale, NJ: Erlbaum.

Harkness, S., \& Super, C. M. (1992b). Parental ethnotheories in action. In I. Siegel, A. V. McGillicuddy-DeLisi, \& J. Goodnow (Eds.), Parental belief systems: The psychological consequence for children (2nd ed., pp. 373-392). Hillsdale, NJ: Erlbaum.

Harrison, L. E. (2004). Introduction: Why culture matters. In L. E. Harrison \& S. P. Huntington (Eds.), Culture matters: How values shape human progress (pp. xviii-xxxiv). New York: Basic Books.

Horowitz, F. D. (2000). Child development and the PITS: Simple questions, complex answers, and developmental theory. Child Development, 71, 1-10.

Huntington, S. P. (2004). Foreword: Culture count. In L. E. Harrison \& S. P. Huntington (Eds.), Culture matters: How values shape human progress (pp. xiii-xvi). New York: Basic Books.

Kağitçibaşi, C. (2007). Family, self, and human development across cultures: Theory and applications (2nd ed.). Mahwah, NJ: Erlbaum.

Kağitçibaşi, C. (2009, February). Strengthening the contributions of child development research to Africa and the majority world. Paper presented at the SRCD-sponsored invitational conference, Strengthening Africa's Contributions to Child Development Research, Victoria, British Columbia, Canada.

Leiderman, P. H., Babu, B., Kagia, J., Kraemer, H. C., \& Liedeman, G. F. (1973). African infant precocity and some social influences during the first year. Nature, 242, 247-249.

LeVine, R. A. (1974). Parental goals: A cross-cultural view. Teachers College Record, 76, 226-239.

LeVine, R. A. (1988). Human parental care: Universal goals, cultural strategies, individual behavior. In R. A. LeVine, P. M. Miller, \& M. M. West (Eds.), New direction for child development: Vol. 40. Parental behavior in diverse societies (pp. 3-12). San Francisco: Josey-Bass.

LeVine, R. A., Dixon, S., LeVine, S., Richman, A., et al. (1994). Child care and culture: Lessons from Africa. New York: Cambridge University Press.

LeVine, R. A., \& LeVine, S. (1988). Parental strategies among the Gusii of Kenya. In R. LeVine, P. Miller, \& M. West (Eds.), New directions for child development: Vol. 40. Parental behavior in diverse societies (pp. 27-36). San Francisco: Josey-Bass.

Marfo, K. (2011). Envisioning an African child development field. Child Development Perspectives, 5, 140-147.

Mwaura, P., \& Marfo, K. (2011). Bridging culture, research, and practice in early childhood development: The Madrasa Resource Centers in East Africa. Child Development Perspectives, 5, 134139.

Myers, R. (2009, February). Connecting worlds in early childhood care and development. Paper presented at the SRCD-sponsored invitational conference, Strengthening Africa's Contributions to Child Development Research, Victoria, British Columbia, Canada.
Nsamenang, A. B. (2009, February). Culture in child development science: An Africentric review. Presented at the SRCD-sponsored invitational conference, Strengthening Africa's Contributions to Child Development Research, Victoria, British Columbia, Canada.

Pence, A. (2011). Early childhood care and development research in Africa: Historical, conceptual, and structural challenges. Child Development Perspectives, 5, 112-118.

Pence, A., \& Marfo, K. (2008). Early childhood development in Africa: Interrogating constraints of prevailing knowledge bases. International Journal of Psychology, 43(2), 78-87.

Richter, L., Norris, S., Pettifor, J., Yach, D., \& Cameron, N. (2007). Cohort profile: Mandela's children: The 1990 birth to twenty study in South Africa. International Journal of Epidemiology, 36, 504511.

Scrimshaw, N. S., \& Guzman, M. A. (1997). A comparison of supplementary feeding and medical care of preschool children in Guatamala, 1959-1964. In M. S. Das, P. Aaby, M. Garenne, \& G. Pison (Eds.), Prospective community studies in developing countries (pp. 133-156). Oxford, UK: Oxford University Press.

Serpell, R. (1984). Research on cognitive development in Sub-Saharan Africa. International Journal of Behavioral Development, 7, 111127.

Serpell, R. (2011). Social responsibility as a dimension of intelligence, and as an educational goal: Insights from programmatic research in an African society. Child Development Perspectives, 5, 126-133.

Stevens, M. J., \& Gielen, U. P. (2007). Toward a global psychology: Theory, research, intervention, and pedagogy. Mahwah, NJ: Erlbaum.

Super, C. M. (1976). Environmental effects on motor development: The case of African infant precocity. Developmental Medicine \& Child Neurology, 18, 561-567.

Super, C. M. (1991). Developmental transitions in cognitive functioning in rural Kenya and metropolitan America. In K. Gibson, M. Konner, \& J. Lancaster (Eds.), The brain and behavioral development: Biosocial dimensions (pp. 225-257). Hawthorne, NY: Aldine.

Super, C. M., \& Harkness, S. (1986). The developmental niche: A conceptualization at the interface of child and culture. International Journal of Behavioral Development, 9, 545-569.

Super, C. M., \& Harkness, S. (1997). The cultural structuring of child development. In J. W. Berry, P. R. Dasen, \& T. S. Saraswathi (Eds.), Handbook of cross-cultural psychology: Vol. 2. Basic processes and human development (2nd ed., pp. 1-39). Boston: Allyn \& Bacon.

Super, C. M., \& Harkness, S. (2002). Culture structures the environment for development. Human Development, 45, 270-274.

Super, M., Harkness, S., Barry, O., \& Zeitlin, M. (2011). Think locally, act globally: Contributions of African research to child development. Child Development Perspectives, 5, 119-125.

Townsend, J. W., Klein, R. E., Irwin, M. H., Owens, W., Yarborough, C., \& Engle, P. L. (1982). Nutrition and preschool mental development. In D. A. Wagner \& H. W. Stevenson (Eds.), Cultural perspectives on child development (pp. 124-145). San Francisco: Freeman.

Walker, S. P., Wachs, T. D., Gardner, J. M., Lozoff, B., et al. (2007). Child development: Risk factors for adverse outcomes in developing countries. Lancet, 369(9556), 145-157.

Weisner, T. S. (1984). A cross-cultural perspective: Ecocultural niches of middle childhood. In A. Collins (Ed.), The elementary school 
years: Understanding development during middle childhood (pp. 335-369). Washington, DC: National Academy Press.

Weisner, T. S. (2000). Culture, childhood, and progress in Sub-Saharan Africa. In L. E. Harrison \& S. P. Huntington (Eds.), Culture matters: How values shape human progress (pp. 141-157). New York: Basic Books.

Whiting, B. B. (1996). The effect of social change on concepts of the good child and good mothering: A study of families in Kenya. Ethos, 24, 3-35.
Worthman, C. M. (1994). Developmental microniche: A concept for modeling relationships of biology, behavior, and culture in development. American Journal of Physical Anthropology Supplement, 18, 210.

Zimba, R. F. (2002). Indigenous conceptions of childhood development and social realities in southern Africa. In H. Keller, Y. H. Poortinga, \& A. Scholmerich (Eds.), Between culture and biology: Perspectives on ontogenetic development (pp. 89-115). Cambridge, UK: Cambridge University Press. 